\title{
STRENGTH DEGRADATION OF CONCRETE BEAMS UNDER CYCLIC LOADING
}

\section{R.C. Fenwick*}

This paper will be presented at the Third South Pacific Regional Conference on Earthquake Engineering, Wellington, May 1983.

\section{SYNOPSIS:}

The mechanisms for resisting flexure and shear in the plastic hinge zones of beams, which are subjected to cyclic loading, are examined. The results of thirty-eight beam tests which have been reported in the literature are reviewed, and criteria are developed for predicting the energy which may be dissipated and the accumulated inelastic deformation that may be sustained before strength degradation occurs.

NOTATION:

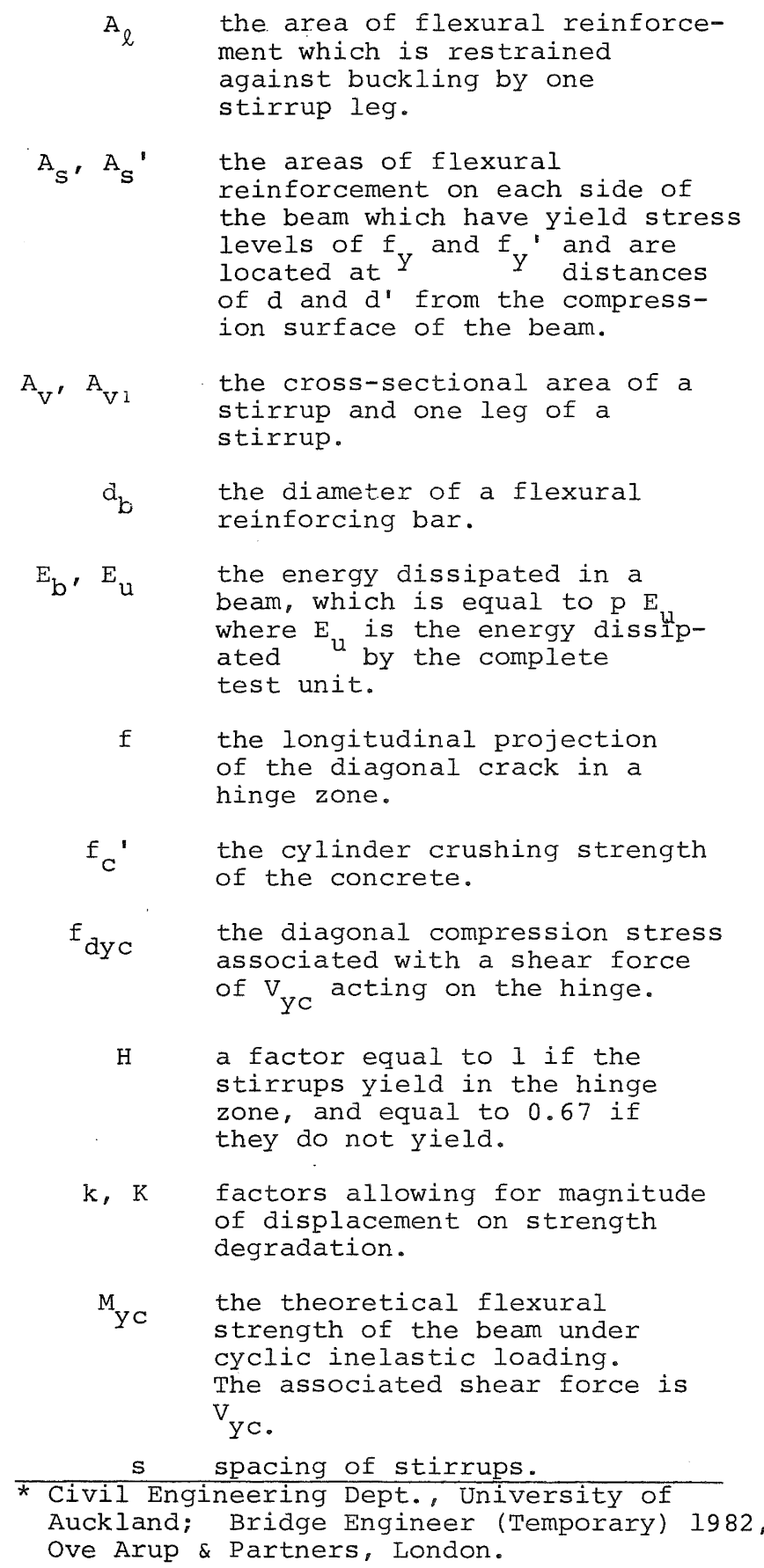

\section{INTRODUCTION :}

Current design rules for multi-storey frame buildings in New Zealand are based on the assumption that under severe seismic conditions plastic hinges may form in the beams. To develop rational design rules it is essential to know how the repeated inelastic displacements, which may be applied to these zones in an earthquake, affect their stiffness and strength. The behaviour of these hinges has been studied in a number of projects. During the last decade and a half several methods have been developed for predicting the flexural response of these zones $(1,2,3)$, and recently a way of calculating the shear deformation has been presented (4). However, before dynamic analyses of structures can be carried out to examine behaviour up to the point where collapse is imminent, it is necessary to have criteria which define how much accumulated inelastic deformation or energy dissipation can be sustained before strength degradation occurs.

In the light of the mechanisms of flexural and shear resistance of hinge zones, the results of several series of beams which have been tested under inelastic cyclic loading conditions are reviewed. Factors influencing strength degradation are identified, and criteria are developed to predict the energy which may be dissipated by a hinge zone.

This study is limited to beams reinforced for shear by stirrups which are normal to the axis of the member. Members containing cross ties in the web or diagonal bars have been excluded from this study. Experimental results show that both these details can lead to a marked improvement in the performance of the hinge zones $(5,6,7)$.

BASIC THEORY FOR HINGE ZONES OF BEAMS:

The basic mechanisms of shear resistance in the plastic hinge zones of concrete beams subjected to inelastic cyclic loading have been out-lined in detail elsewhere (4). In this paper only a brief outline of the main features is given.

The first complete inelastic load 
cycle which is applied to a beam causes the Elexural reinforcement to yield in tension, first on one side of the member and then on the other side. When, at the end of the cycle the load is removed, an open crack exists right through the beam owing to the tension yield strain in the steel. Under subsequent loading the flexural compression force must be resisted by the reinforcement in the compression zone, unless or until this force reaches a magnitude which is sufficient to cause the steel to yield in compression and so close the cracks in the concrete. Thus the compression zone reinforcement carries a very much greater proportion of the compression force than would be indicated by standard flexural theory. Furthermore, the cyclic loading and unloading of the concrete (8) together with the cracking and disruption caused by the yielding of the deformed bars which slip towards the cracks, reduce the stiffness and strength of the concrete in the compression zone. Consequently the normal code rules which have been developed for predicting the ultimate flexural strength of members under monotonic loading conditions do not apply to the inelastic cyclic case.

In beams with equal areas of flexural tension and compression reinforcement the internal level arm, after the first complete inelastic load cycle, is equal to the distance between the reinforcement centroids $\left(d-d^{\prime}\right)$. Provided the ratio of the flexural steel area lies in the range of 0.5 to 2 there is little loss in accuracy in using this value for the internal lever arm. With this approximation the flexural strength is given by:

$M_{y C}=\left(d-d^{\prime}\right) \quad A_{s} \quad f_{y}$

The subscripts $y$ and $c$ are used to indicate that the parameter (in this case a bending moment) refers to cyclic loading conditions where the flexural reinforcement in the compression zone has been previously yielded in tension. The shear force associated with this moment is given by:

$\mathrm{V}_{\mathrm{YC}}=\mathrm{M}_{\mathrm{YC}} \cdot \mathrm{V} / \mathrm{M}$

where $V / M$ is the moment to shear ratio for the direction of loading being considered.

Often the internal lever arm ( $\left.d-d^{\prime}\right)$ which acts after the compression zone steel has been yielded in tension is smaller than the internal lever arm corresponding to initial conditions. can lead to a decrease in the maximum bending moment sustained in the second cycle of inelastic loading. Such a case is illustrated in Fig. 5. In subsequent cycles the moment capacity increases as a result of strain hardening of the reinforcement.

With the reversal of the direction of the shear force, intersecting diagonal cracks form through the beam dividing the concrete into a series of diamond-shaped blocks, as illustrated in Fig. 1a. Under these conditions the shear resisting mechanisms of aggregate interlock and dowel actions (16) are ineffective, and as a result no shear can be resisted by the concrete $\left(\mathrm{V}_{\mathrm{C}}=0\right)$. All the shear is resisted by $\mathrm{a}$ truss-like action in which the stirrups act as ties and the concrete resists the diagonal compression forces (see Fig. 1b).

Figure 2 shows the forces acting across a diagonal crack in a beam when a shear of $\mathrm{V}_{\mathrm{yc}}$ is applied. As all the shear is resisted by the stirrups the equilibrium requirements are given by the equation:

$\mathrm{V}_{\mathrm{yC}}=\mathrm{A}_{\mathrm{v}} \mathrm{f}_{\mathrm{Vs}} \mathrm{f} / \mathrm{s}$

where $A_{V} f_{v s}$ is the cross sectional area of the stirrup times the stress acting in it and $\mathrm{f} / \mathrm{s}$, which is the longitudinal projection of the diagonal crack divided by the stirrup spacing, is the number of stirrups crossing the crack.

The inclination of the diagonal cracks and the diagonal compression forces in the web may be found by studying the compatibility requirements of the hinge zone. These are illustrated in Fig. 3 where the flexural deformations in a length $f$ of the hinge are considered. The compression zone is subjected to circular bending so that a rotation $\theta$ develops between the tangents at points $A$ and $C$. As a result of this curvature point $C$ rises by a distance of $f \Theta / 2$ from the tangent at point $A$. The diagonal $C B^{\prime}$ rotates through the same angle $\theta$ causing point $B^{\prime}$ to drop a distance of $f \theta$ from point $C$. Consequently the increase in depth of the beam measured from $A$ to $B^{\prime}$ is equal to $\theta \mathrm{f} / 2$. It is this movement which generates stresses in the stirrups, and if the rotations exceed a certain critical level, $\theta_{\text {crit" }}$ the stirrups will yield. This critical value can be found by equating the yield extension of the stirrups to the increase in depth of the beam. Thus:

$\theta_{\text {crit }} \mathrm{f} / 2=\mathrm{S}_{\ell} \mathrm{f}_{\mathrm{Vy}} / \mathrm{E}$

where $S_{\ell}$ is the overall (outside to outside) length of the stirrup, $f_{v y}$ is the yield stress in the stirrup and $E$ is the elastic modulus. As the average curvature between $A$ and $B$ is equal to $\theta / f$ equation 4 may be rewritten as:

$\Psi_{\text {crit }}=2 \mathrm{~S}_{\ell} \mathrm{f}_{\mathrm{VY}} /\left(\mathrm{E} \mathrm{f}^{2}\right)$

where $\Psi_{\text {crit }}$ is the hinge zone curvature which causes the stirrups to reach the yield point. Any curvature in excess of this value leads to an incremental yield extension of the stirrups, $\Delta S_{i}$, which is given by:

$\Delta \mathrm{S}_{i}=\left(\Psi-\Psi_{\text {crit }}\right) \mathrm{f}^{2} / 2$

and the resultant yield extension at any stage is found by summing all the incremental extensions. In these calculations 


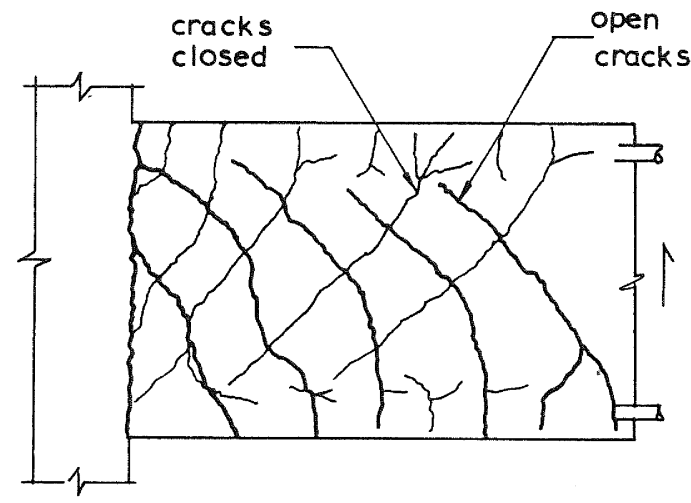

(a) Crack Pattern Under Cyclic Loading

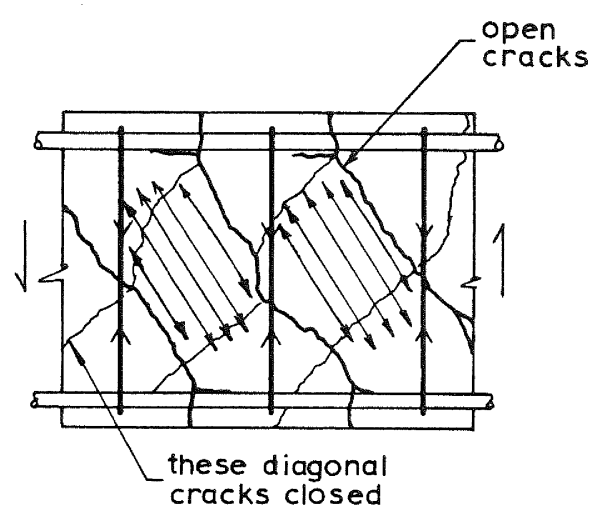

(b) Truss Action in Hinge

Fig. 1 - Crack Pattern and Truss Action in Hinge Zone

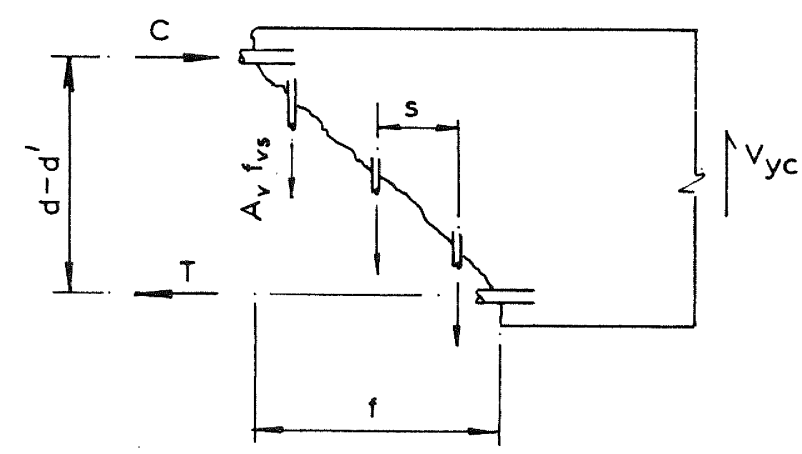

Fig. 2 - Equilibrium Requirements in Hinge Zone
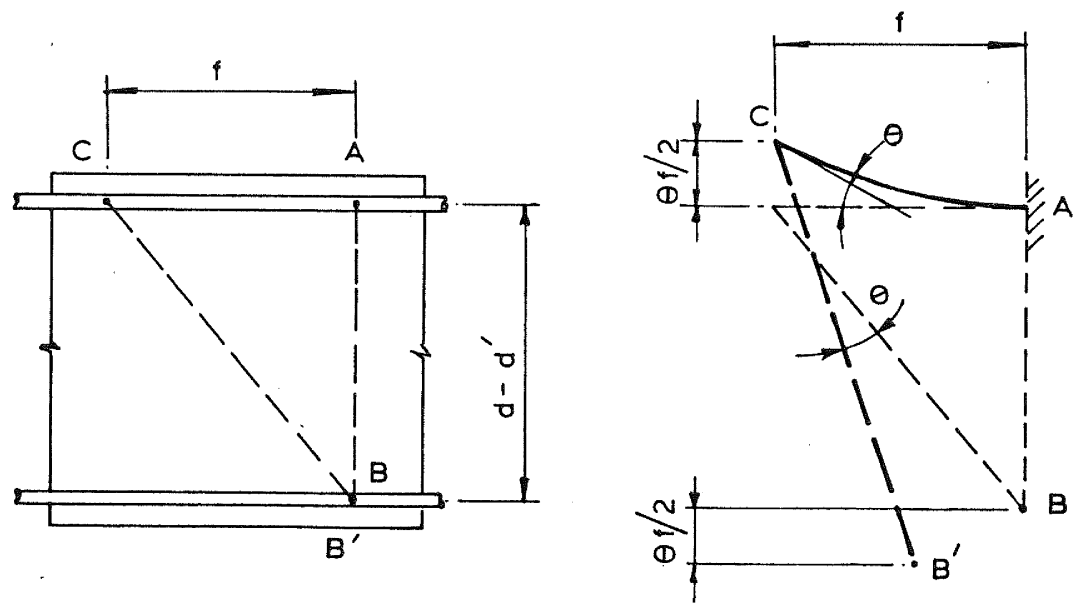
the curvatures are measured from the previous zero load position.

Strain hardening of the flexural reinforcement allows the shear force to increase above the $V_{y c}$ value. However, as the stirrups usually strain harden at about the same rate as the flexural reinforcement, the value of $f$, as given in equation 3 does not change. If deformations are to be calculated some allowance needs to be made for the increase in $\Psi_{\text {crit }}$ arising from this strain hardening (4).

The effect of the yielding extensions of the stirrups on the deformation of a hinge zone can be visualised from the truss analogy, as illustrated in Fig. 4. For a beam to be capable of resisting shear forces which reverse in direction, diagonal compression forces must be able to develop in either direction. With the shear forces acting in the clock-wise direction, as shown in Fig. 4a, diagonal compression forces are sustained between $D$ and $B$, and $E$ and $C$. The stirrup between $B$ and $E$ has $Y$ ielded. The diagonal members $\mathrm{AE}$ and $\mathrm{BF}$ carry no load, and due to the extension of the stirrups they contain wide cracks (representing the diagonal cracks in the beam). When the load is removed

elastic recovery occurs in the truss member, but the cracks in $\mathrm{AE}$ and $\mathrm{BF}$ remain open owing to the yield extension of $\mathrm{BE}$. When the load reverses these cracks have to close so that they. can sustain the necessary diagonal compression forces. The shear displacement associated with this crack closure gives rise to the well known shear pinching characteristic in the load deflection curves, and it is this which is responsible for most of the stiffness degradation that occurs at low load levels.

FACTORS INFLUENCING STRENGTH DEGRADATION IN BEAMS:

When a series of inelastic load cycles are applied to a beam the load sustained at the peak displacements usually increases

due to strain hardening and then decreases due to stiffness or strength degradation. Stiffness degradation is associated with the yielding extension of the stirrups while strength degradation occurs due to excessive buckling of the reinforcement or the disintergration of the concrete in the web of the beam. In some beam tests strength degradation clearly limits the load capacity of the beam after a number of cycles, see Fig. $6 \mathrm{a}$ and $\mathrm{b}$, while in others, with the degree of stiffness degradation that has occurred, the amplitude of displacement applied at the end of the test is insufficient to develop the maximum shear resistance. Beam T2A, which is shown in Fig. 6c, illustrates this type of behaviour. In the last cycles of this test a greater displacement would have enabled the shear that was resisted to have increased to its previous level.

In Fig. 5 for beam TlB the maximum shear sustained in each half cycle of loading is plotted against the energy dissipated to that stage. This curve is typical of many beams. The peak shear forces initially increase and then decrease gradually with energy dissipation until the maximum shear falls to close to the $V_{y c}$ value. Further energy dissipation results in a rapid decrease in strength. In this paper strength degradation is assumed to occur when the beam can no longer sustain a shear of $\mathrm{V}_{\mathrm{yc}^{\circ}}$

In developing criteria to predict strength degradation it was necessary to identify those beam tests in which strength degradation had not occurred when the test was abandoned. Some judgement was required for this. For example the load deflection curves of beams 88-32-RV5 and TlB, illustrated in Fig. $6 a$ and $b$, show clear evidence of strength degradation, but this is not the case with beam T2A, see Fig. $6 \mathrm{c}$. of the thirty-eight beam tests examined in this paper some six beams did not show clear evidence of strength degradation and these results were disregarded when an empirical equation was derived from the test results.

When strength degradation occurs the web of the beam disintegrates, and it can no longer sustain the diagonal compression forces required to resist the shear. This observation suggests that the diagonal compression stress in the web is one of the principle factors influencing strength degradation. measure of this action the diagonal compression stress sustained by the concrete due to a shear of $\mathrm{V}_{\mathrm{yc}}$ was calculated for each beam. It was converted into a dimensionless ratio by dividing by the cylinder strength of the concrete. In sumbols this ratio was $\mathrm{f}_{\mathrm{dyc}} / \mathrm{f}_{\mathrm{c}}$ '.

Figure 8 shows a diagonal compression force acting in a beam. If the inclination of this force $D$ to the axis of the beam is $\alpha$ and if it is sustained by one stirrup, then:

$A_{V} f_{V S}=D \sin \alpha$

If the width of the web is $b$ and the stirrup spacing is $s$ the diagonal compression stress is given by:

$f_{\text {dyc }} s \mathrm{~b} \sin \alpha=\mathrm{D}$

and hence

$f_{d y c}=\frac{A_{v} f_{v s}}{s b \sin ^{2} \alpha}$

Two different cases need to be recognised to calculate the diagonal compression stress from this equation.

(1) If the stirrups yield, the inclination of the diagonal crack, and hence the compression forces is given by:

$$
\alpha=\tan ^{-1}\left(d-d^{\prime}\right) / f
$$

where $f$ may be found from equation 3 , and $f_{v s}$ is equal to $f_{v y}$ 


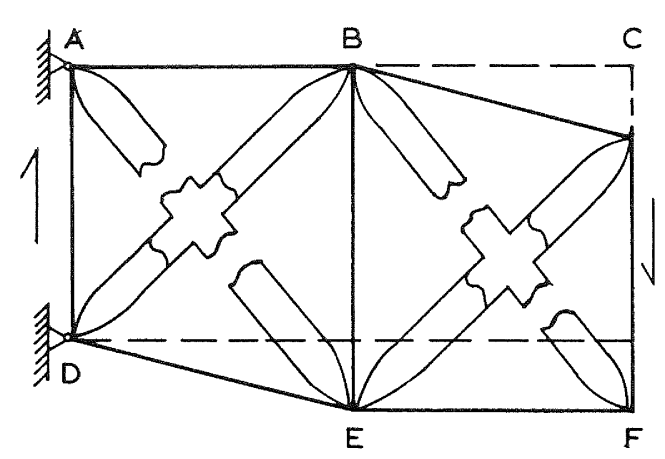

(a) Shear Clockwise

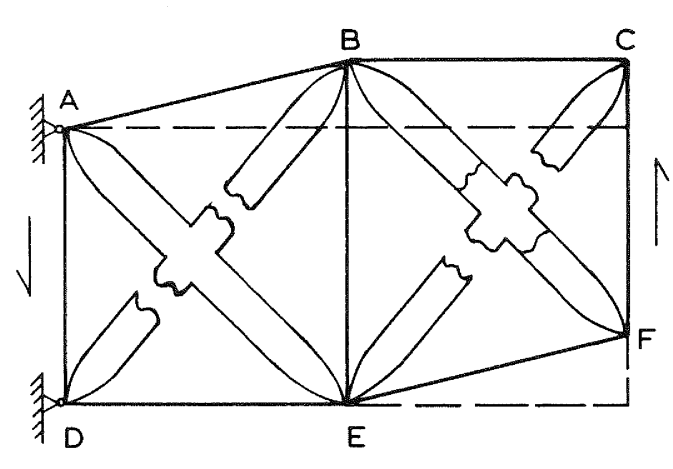

(b) Shear Anti-clockwise

Fig. 4 - Truss Analogy for Shear Resistance of Hinge zone

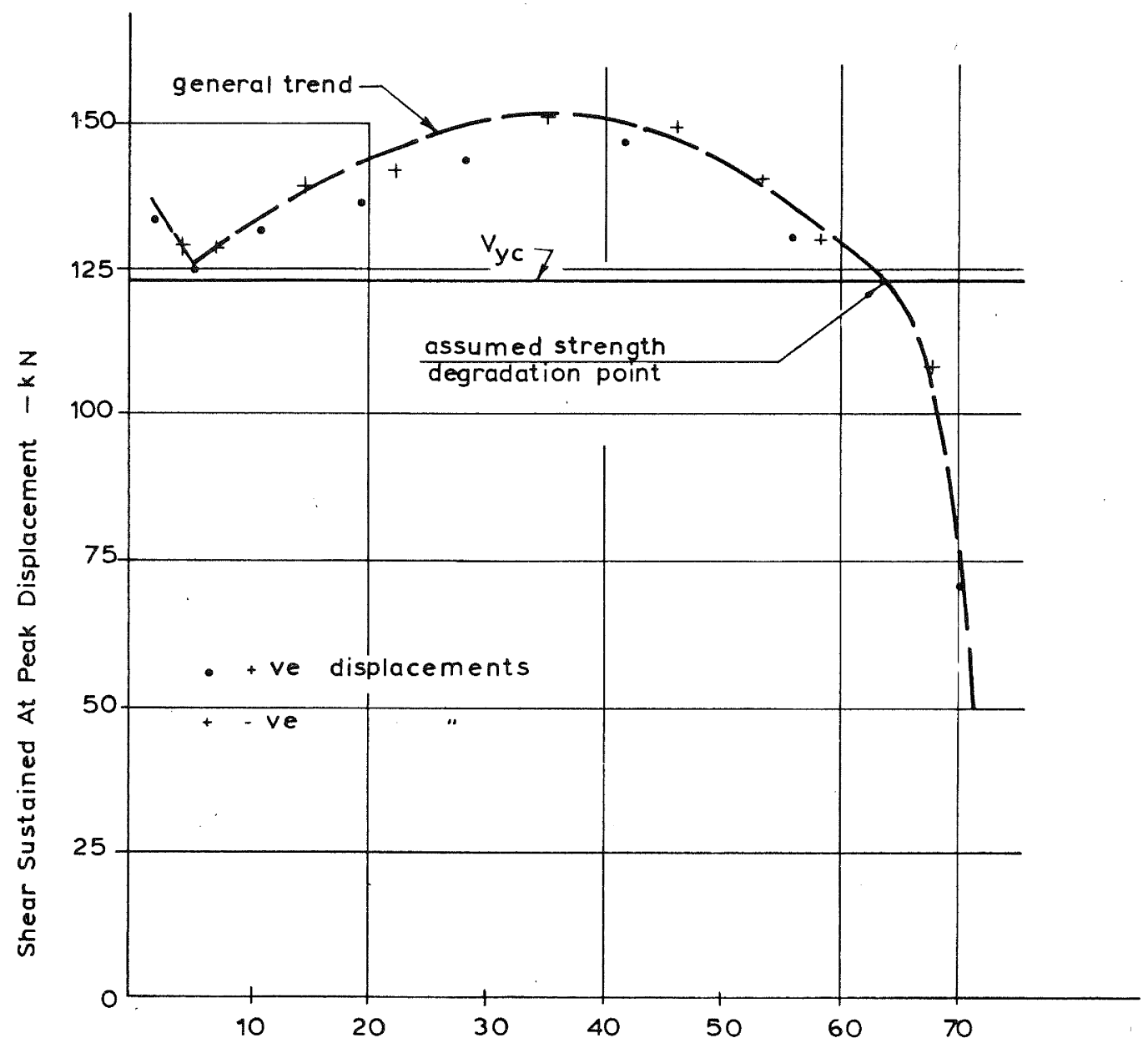

Energy Dissipated in K太Nm. Beam $T-1 B$

Fig. 5. Load Sustained at Peak Displacement versus Energy Dissipated (Beam TlB) 
(2) The stirrups cannot yield if the stirrup yield force "A $f$ " is greater than the maximum sheary force on the beam, and they are unlikely to yield if $\mathrm{A}_{\mathrm{V}} \mathrm{f}_{\mathrm{vy}}$ exceeds $\mathrm{V}_{\mathrm{yc}}{ }^{\circ}$. In this case only one stirrup can cross each crack, and consequently the value of $f$ may be taken as s. For this condition the diagonal compression stress is given by:

$$
f_{d y c}=\frac{V_{y c}}{s b \sin ^{2} \alpha}
$$

where

$$
\alpha=\tan ^{-1}\left(d-d^{\prime}\right) / s
$$

From the test results it was apparent that the energy dissipated by the beams increased with the flexural strength of the member. To allow for this effect the energy dissipated at strength degradation was divided by the average of the $\mathrm{M}_{\mathrm{yc}}$

values determined for positive and negative hinge rotations. The resultant non-dimensional value is analogous to the sum of the inelastic rotations occurring in a plastic hinge behaving in a perfectly elastic-plastic mode. In symbols this ratio is given by $E_{b} / M_{\text {ycav' }}$ where $E_{b}$ is the energy dissipated in the beam. reinforcement ratios of $A_{S} f_{y} / b d$ and $\left(A_{S} f_{Y}-A_{S^{\prime}} f_{Y^{\prime}}{ }^{\prime}\right) / b d$ were evaluated in case the influence of the flexural strength on dissipated strength was not linear. However, inspection of plots of the results failed to show any significant influence of these parameters in the range of variable covered by the tests.

Two ratios which measure the restraint provided against buckling of the reinforcement are:

i) The stirrup spacing $s$ divided by the diameter of the flexural reinforcement $d_{b}$, and

ii) The area of longitudinal reinforcement A which is restrained against buckling by one stirrup leg divided by the cross sectional area of that leg $A_{v 1}$. These two ratios were adjusted so that they were close to unity in typical test beams, and they were evaluated for all the tests. The first ratio was $s / 4 d_{b}$ ' and the second was $A_{\ell} / 8 A_{V I}$.

It was anticipated that yielding of the stirrups would reduce the capacity of a hinge zone to dissipate energy in a number of ways. The growth in depth of the beam, which is associated with stirrup yielding, causes the reinforcement to bulge in the hinge zone. This action is likely to reduce the buckling resistance of the reinforcement. The disruption caused by the yielding of the stirrups and the displacements associated with the movement is likely to reduce the capacity of the concrete to sustain the diagonal compression stresses. A series of regression analyses were made to see if the magnitude of the yield extension of the stirrups could be correlated with the energy dissipated at strength degradation. However, no significant effect could be detected though a major difference was noted in the behaviour of those beams with yielding stirrups as compared with those containing non-yielding stirrups. This phenomenon may be seen from the load deflection diagrams shown in Fig. 6. The stirrups did not yield in beam 88-32-RV5 which is shown in Fig. $6 a$. The load deflection curve is convex and there is no sign of shear pinching. The curves for beam $T 2 A$ and $T 1 B$, are typical of those with yielding stirrups. The magnitude of the shear pinching can be seen to increase with each inelastic load cycle.

of the thirty-eight beams examined in this paper the theory outlined earlier indicated that in eleven of these the shear reinforcement would not yield. four of the beams tested by Brown, and one tested by Scribner, the maximum shear force that was sustained was less than the force required to yield a stirrup. In a further six beams tested by Brown the necessary curvature and sustained shear force were insufficient to initiate yielding. The beams with non-yielding shear reinforcement are identified in Table 2 .

There were two possible effects arising from the use of different grades of reinforcement. The higher strength steels undergo more strain-hardening than the lower grades, and this would lead to longer hinge zones with a corresponding decrease of curvature ductilities. Some enhancement in the energy dissipation performance of the hinge could well be expected to follow from this. However, the beneficial effect could in part be offset by the higher diagonal compression stresses induced in the beam due to the enhanced shear capacity associated with the strain hardened moment of resistance. To allow any general trend of the reinforcement grade to be assessed from the test results the ratio obtained by dividing the yield point of the flexural reinforcement expressed in $\mathrm{M} \mathrm{Pa}$ by 275 was evaluated for each beam.

\section{INTERPRETATION OF TEST RESULTS:}

Details of the beam tests examined in this paper are given in tables 1 and 2 and the method of testing the members is illustrated in Fig. 7. In all cases the beams were tested as free cantilevers, but the springing details varied considerably. In all but one test the beam flexural reinforcement yielded in the springing block or column, and this energy was dissipated in this zone. compare the results of the different test series it was necessary to assess the proportion of the total energy that was dissipated in the beam.

In the series of tests carried out by Brown (9), Ismail(10) studied the bond performance of the beam flexural reinforcement in the springing block, see Fig. 7a. From measurements he made on the reinforcement the proportion of the displacement of the load that arose from 


\begin{tabular}{|c|c|c|c|c|c|c|c|c|c|c|c|c|}
\hline $\begin{array}{l}\text { Beam } \\
\text { Reference }\end{array}$ & $\begin{array}{r}b \\
m n\end{array}$ & $\mathrm{~d}$ & $\mathrm{~d}$ & $\begin{array}{l}M / V \\
m n\end{array}$ & $\mathrm{FPa}_{\mathrm{C}}^{\prime}$ & $\begin{array}{l}\text { FLEXURAL RE } \\
\text { NO-d }{ }_{\mathrm{b}}-\mathrm{f}_{\mathrm{y}} \\
\mathrm{mm} \mathrm{MPa}\end{array}$ & $\begin{array}{l}\text { NFORCEMENT } \\
\text { No-d } d_{b}-f_{y}^{y} \\
m m\end{array}$ & Stps. - S -E vy & ${ }^{M} y c$ & ${ }_{y C}$ & $\mathbf{p}$ & $\mathbf{E}_{\mathbf{u}}$ \\
\hline \multicolumn{13}{|l|}{ BROWN" } \\
\hline $88-35-R V 5$ & 152 & 251 & 54 & 1524 & 41.4 & $2 \times 25-317$ & $2 \times 25-317$ & $2 \times 9.5-127-340$ & 65 & 65 & 0.49 & 107 \\
\hline $88-35-R V 10$ & 152 & 251 & 54 & 1524 & 38.6 & $2 \times 25-324$ & $2 \times 25-317$ & $2 \times 9.5-127-340$ & 66 & 65 & 0.49 & 80 \\
\hline $66-35-R V 5$ & 152 & 254 & 51 & 1524 & 39.3 & $2 \times 19-338$ & $2 \times 19-338$ & $2 \times 9.5-127-340$ & 40 & 40 & 0.55 & 81 \\
\hline $66-35-R V 10$ & 152 & 254 & 51 & 1524 & 36.6 & $2 \times 19-324$ & $2 \times 19-331$ & $2 \times 9.5-127-340$ & 38 & 39 & 0.55 & 40 \\
\hline $88-32-R V 10$ & 152 & 251 & 54 & 1524 & 42.8 & $2 \times 25-303$ & $2 \times 2 b-317$ & $2 \times 9.5-51-340$ & 62 & 63 & 0.49 & 157 \\
\hline $88-32-R V 5$ & 152 & 251 & 54 & 1524 & 39.3 & $2 \times 25-303$ & $2 \times 25-310$ & $2 \times 9.5-51-340$ & 62 & 65 & 0.49 & 228 \\
\hline $66-32-\mathrm{RVS}$ & 152 & 254 & 51 & 1524 & 36.6 & $2 \times 19-324$ & $2 \times 19-324$ & $2 \times 9.5-51-340$ & 38 & 38 & 0.40 & 142 \\
\hline $66-32-R V 10$ & 152 & 254 & 51 & 1524 & 33.1 & $2 \times 19-317$ & $2 \times 19-331$ & $2 \times 9.5-51-340$ & 37 & 39 & 0.55 & 102 \\
\hline $86-35-R V 5$ & 152 & 251 & 54 & 1524 & 34.5 & $2 \times 25-310$ & $2 \times 19-317$ & $2 \times 9.5-127-340$ & 64 & 37 & 0.52 & 93 \\
\hline $86-35-R V 10$ & 152 & 251 & 54 & 1524 & 34.5 & $2 \times 25-310$ & $2 \times 19-317$ & $2 \times 9.5-127-340$ & 64 & 37 & 0.53 & 55 \\
\hline $88-34-R V 5$ & 152 & 251 & 54 & 762 & 34.5 & $2 \times 25-310$ & $2 \times 25-31 \%$ & $3 \times 9.5-102-340$ & 63 & 65 & 0.49 & 48 \\
\hline $88-34-R V 10$ & 152 & 251 & 54 & $7 \in 2$ & 39.3 & $2 \times 25-317$ & $2 \times 25-310$ & $2 \times 9.5-102-340$ & 65 & 63 & 0.49 & 40 \\
\hline $66-35-R V 5$ & 152 & 254 & 51 & 762 & 35.9 & $2 \times 19-310$ & $2 \times 19-317$ & $2 \times 9.5-127-340$ & 37 & 37 & 0.55 & 23 \\
\hline $66-35-\operatorname{RV} 10$ & 152 & 254 & 51 & 762 & 37.2 & $2 \times 19-324$ & $2 \times 12-321$ & $2 \times 9.5-127-340$ & 38 & 38 & 0.55 & 23 \\
\hline \multicolumn{13}{|l|}{ SCRIBER * } \\
\hline 1 & 203 & 218 & 33 & 1054 & 34.3 & $2 \times 19-337$ & $2 \times 16-357$ & $2 \times 6.4-51-294$ & 36 & 27 & 0.65 & 36 \\
\hline 3 & 203 & 257 & 46 & 1054 & 34.3 & $3 \times 19-337$ & $3 \times 16-357$ & $2 \times 6.4-64-294$ & 62 & 46 & 0.65 & 34 \\
\hline 5 & 203 & 218 & 33 & 787 & 27.4 & $2 \times 19-363$ & $2 \times 16-363$ & $2 \times 6.4-51-294$ & 39 & $27^{\circ}$ & 0.65 & $30 "$ \\
\hline 7 & 203 & 257 & 46 & 1054 & 27.4 & $3 \times 19-363$ & $3 \times 16-363$ & $2 \times 9.5-64-520$ & 67 & 46 & 0.65 & 41 \\
\hline 9 & 254 & 307 & 46 & 1524 & 34.1 & $4 \times 25-415$ & $4 \times 22-340$ & $2 \times 9.5-64-294$ & 225 & $14 i$ & 0.65 & 149 \\
\hline 11 & 254 & 307 & 46 & 1219 & 34.1 & $4 \times 25-415$ & $4 \times 22-340$ & $2 \times 9.5-64-294$ & $22 b$ & 141 & $0.6 \mathrm{~b}$ & 77 \\
\hline \multicolumn{13}{|l|}{ FONG * } \\
\hline FAl & 200 & 442 & 58 & 923 & 30.0 & $5 \times 20-290$ & $5 \times 20-290$ & $\left.\begin{array}{l}3-6 \\
2-10\end{array}\right\} \quad 100-300$ & 175 & 175 & 0.85 & 42.3 \\
\hline$F \perp B$ & 200 & 442 & 58 & 1329 & 30.0 & $5 \times 20-290$ & $5 \times 20-290$ & $\left.\begin{array}{c}4-6 \\
1-10\end{array}\right\} \quad 100-300$ & 175 & 175 & 0.85 & 67.5 \\
\hline F2A & 200 & 442 & 58 & 1735 & 34.7 & $5 \times 20-280$ & $5 \times 20-280$ & $5-6-100-300$ & 169 & 269 & 0.85 & 79.6 \\
\hline$F 2 \mathrm{~B}$ & 200 & 442 & 58 & 2242 & 34.7 & $5 \times 20-280$ & $5 \times 20-280$ & $5-6-100-300$ & 169 & 169 & 0.85 & 93.6 \\
\hline F3A & 200 & 442 & 58 & 1329 & 27.7 & $5 \times 20-280$ & $5 \times 16-298$ & $\left.\begin{array}{c}4-6 \\
1-10\end{array}\right\} \quad 100-300$ & 164 & 123 & 0.85 & 37.1 \\
\hline F5A & 200 & 444 & 56 & 1326 & 48.6 & $5 \times 16-392$ & $5 \times 16-392$ & $\left.\begin{array}{l}4-6 \\
1-10\end{array}\right\} \quad 100-300$ & 153 & 153 & 0.85 & 111.0 \\
\hline $\begin{array}{l}\text { F5B } \\
\text { TANKAT }\end{array}$ & 200 & 444 & 56 & 923 & 48.6 & $5 \times 16-392$ & $5 \times 16-392$ & $\left.\begin{array}{l}3-6 \\
2-10\end{array}\right\} \quad 100-300$ & 153 & 153 & 0.85 & 50.0 \\
\hline TIA & 200 & 440 & 60 & 1500 & 33.2 & $5 \times 20-311$ & $5 \times 20-311$ & $\left.\begin{array}{l}2-10 \\
1-6\end{array}\right\} \quad 100-307$ & 184 & 184 & 0.85 & 51 \\
\hline$T 1 B$ & 200 & 440 & 60 & 1500 & 42.1 & $5 \times 20-311$ & $5 \times 20-311$ & $\left.\begin{array}{l}2-10 \\
1-6\end{array}\right\} \quad 100-307$ & 184 & 184 & 0.85 & 67 \\
\hline $\mathrm{T} 2 \mathrm{~A}$ & 200 & 440 & 60 & 1500 & 37.6 & $5 \times 20-306$ & $5 \times 20-306$ & $\left.\begin{array}{l}2-10 \\
1-6\end{array}\right\} \quad 100-307$ & 182 & 182 & 0.85 & 56 \\
\hline T2B & 200 & 440 & 40 & 1500 & 37.6 & $5 \times 20-306$ & $3 \times 20-306$ & $\left|\begin{array}{l}2-10 \\
1-6\end{array}\right| \quad 100-307$ & 196 & 114 & 0.85 & 56 \\
\hline T3A & 200 & 440 & 60 & $\left.\begin{array}{l}1490 \\
2310\end{array}\right\}$ & 35.6 & $5 \times 20-306$ & $5 \times 20-306$ & $\left.\begin{array}{l}2-10 \\
1-6\end{array}\right\} \quad 100-307$ & 187 & 187 & 0.85 & 75 \\
\hline $\mathrm{T} 3 \mathrm{~B}$ & 200 & 440 & 60 & $\left.\begin{array}{l}1490\} \\
2350\end{array}\right\}$ & 35.6 & $5 \times 20-306$ & $5 \times 20-306$ & $\left.\begin{array}{l}2-10 \\
1-6\end{array}\right\} \quad 100-30 \%$ & 187 & 187 & 0.85 & 91 \\
\hline $\mathrm{T} 4 \mathrm{~A}$ & 200 & 440 & 60 & $\left.\begin{array}{l}1230 \\
2020\end{array}\right\}$ & 33.4 & $5 \times 20-312$ & $5 \times 20-312$ & $\left.\begin{array}{l}2-10 \\
1-6\end{array}\right\} 100-307$ & 190 & 190 & 0.85 & 67 \\
\hline$T 4 B$ & 200 & 440 & 60 & $13 \infty$ & 33.4 & $5 \times 20-312$ & $\begin{array}{r}5 \times 20-312\} \\
10 \times 10-296\end{array}$ & $\left.\begin{array}{l}2-10 \\
1-6\end{array}\right\} \quad 100-30 \%$ & 270 & 180 & 0.85 & 82 \\
\hline $\begin{array}{l}\text { UNIT } 2 \\
\text { POPOV }\end{array}$ & 250 & 455 & 45 & 1815 & 36.2 & $\left.\begin{array}{l}2-28 \\
1-24\end{array}\right\}-2 \% 7$ & $\left.\begin{array}{l}2-28 \\
1-24\end{array}\right\}-277$ & $\left.\begin{array}{l}2-10 \\
1-6\end{array}\right\} \quad 100-320$ & 193 & 193 & 1.0 & 94 \\
\hline 43 & 381 & 641 & y5 & 1980 & 34.7 & $6 \times 28-414$ & $6 \times 28-414$ & $2 \times 12-7-76-414$ & 893 & 893 & 0.61 & 509 \\
\hline 35 & 381 & 641 & 95 & 1980 & 26.6 & $6 \times 28-462$ & $6 \times 28-462$ & $2 \times 9.5-144-366$ & 994 & 994 & 0.61 & 117 \\
\hline
\end{tabular}




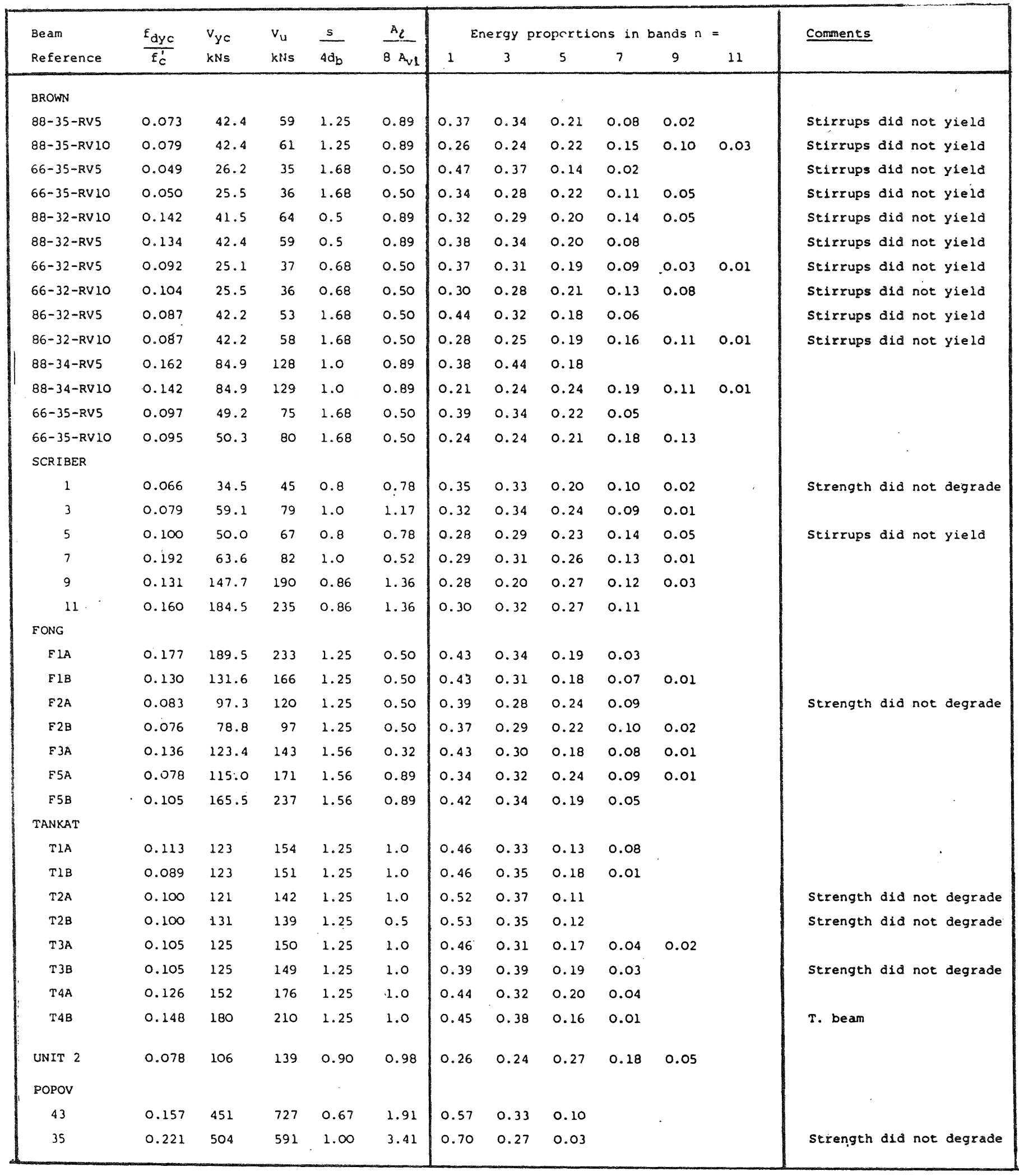




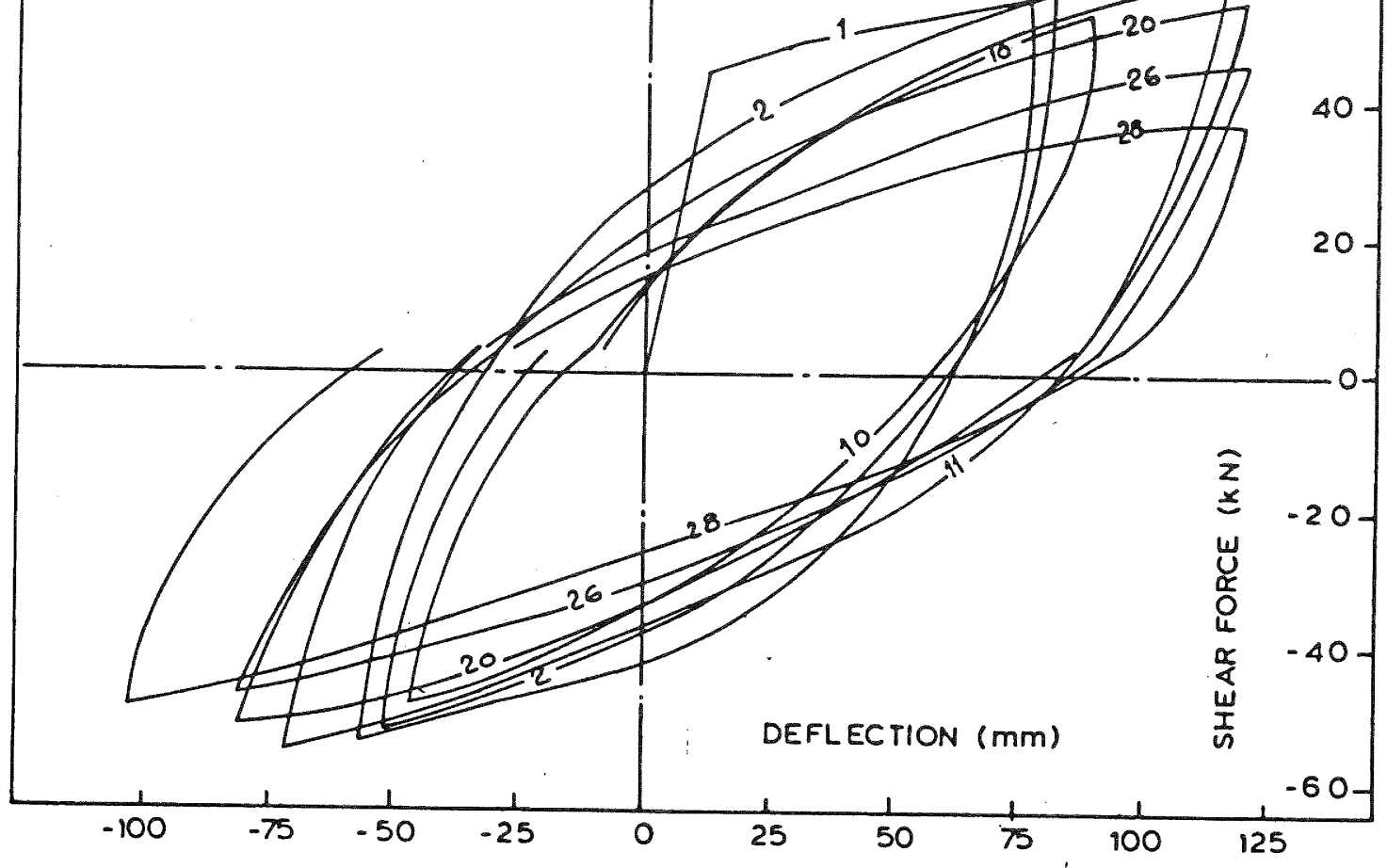

(a) BEAM - BROWN, 88-32RVS

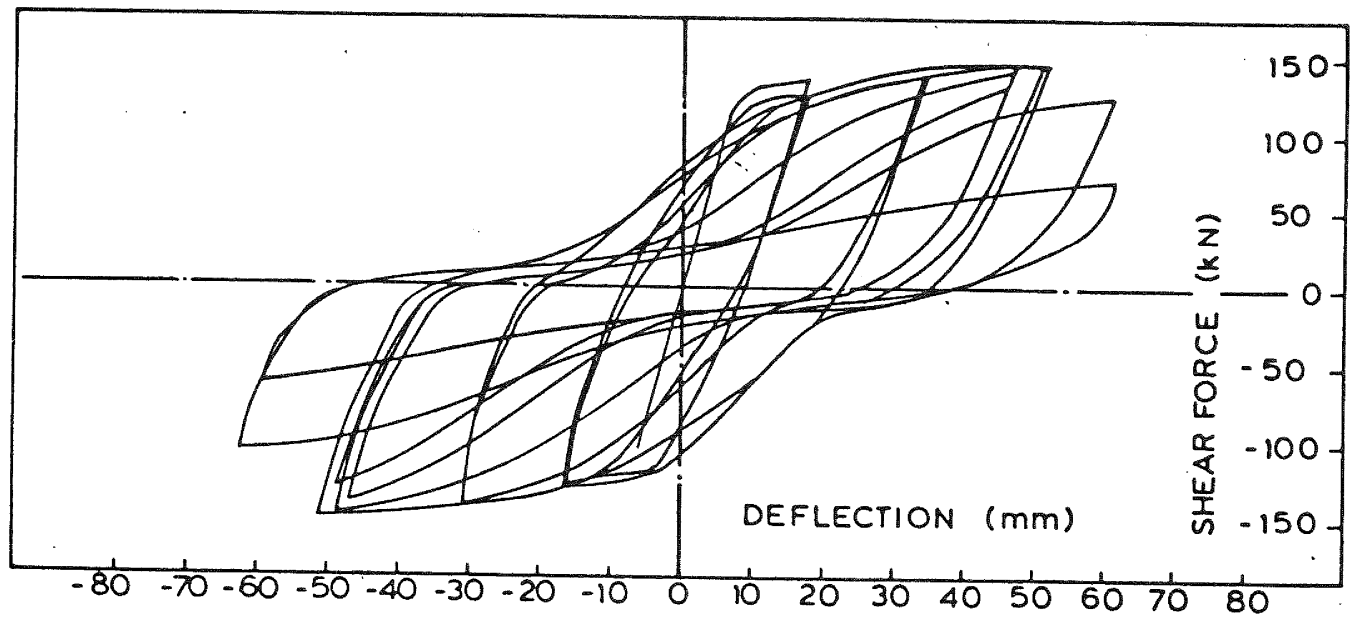

(b) BEAM - TANKAT, T1B

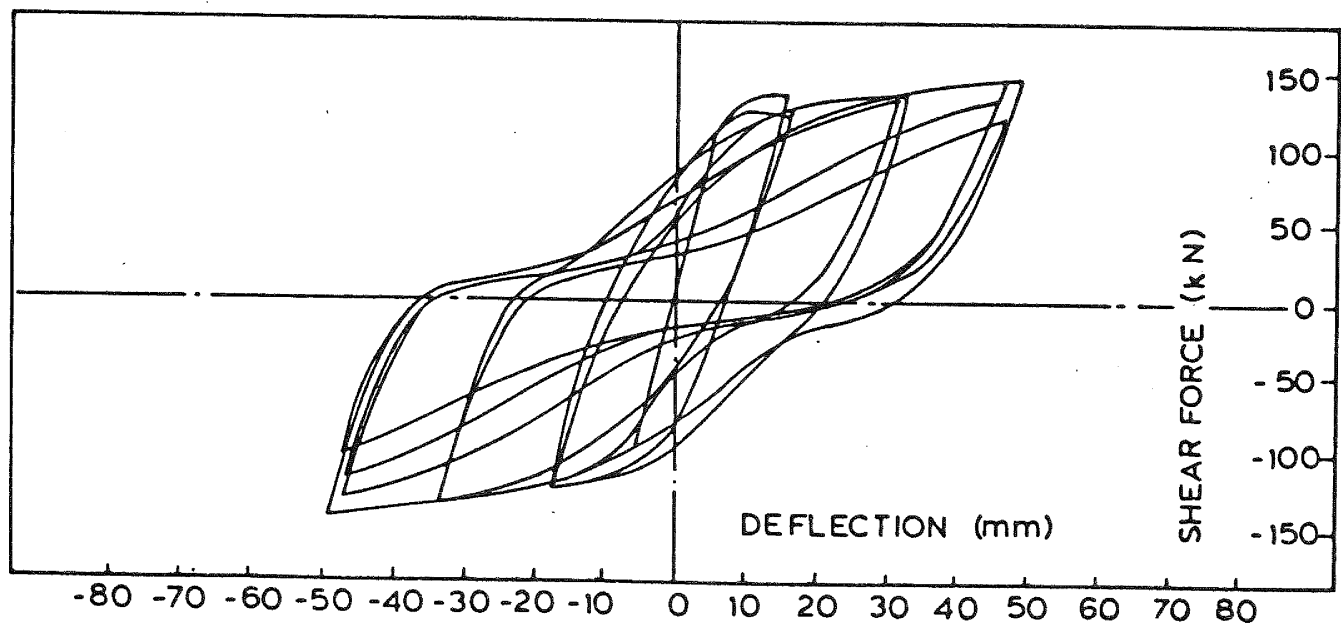

(c) BEAM - TANKAT, T2A

Fig. 6 - Load Deflection Curves for Three Test Beams 


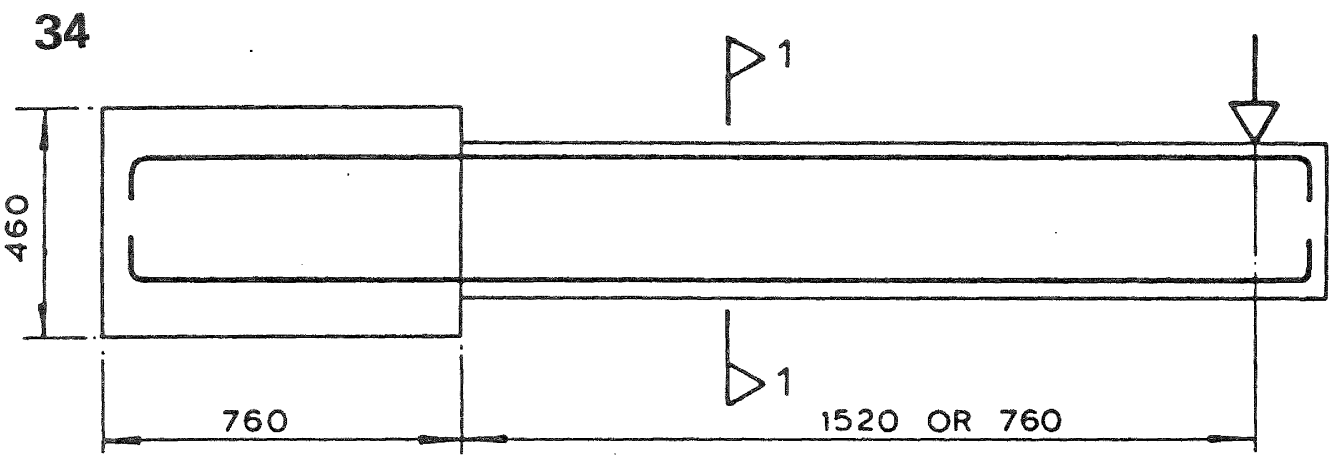

(a) BEAMS TESTED BY BROWN (9)

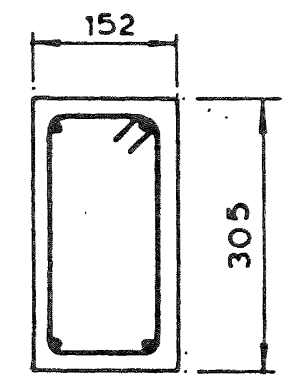

SECTION $1-1$
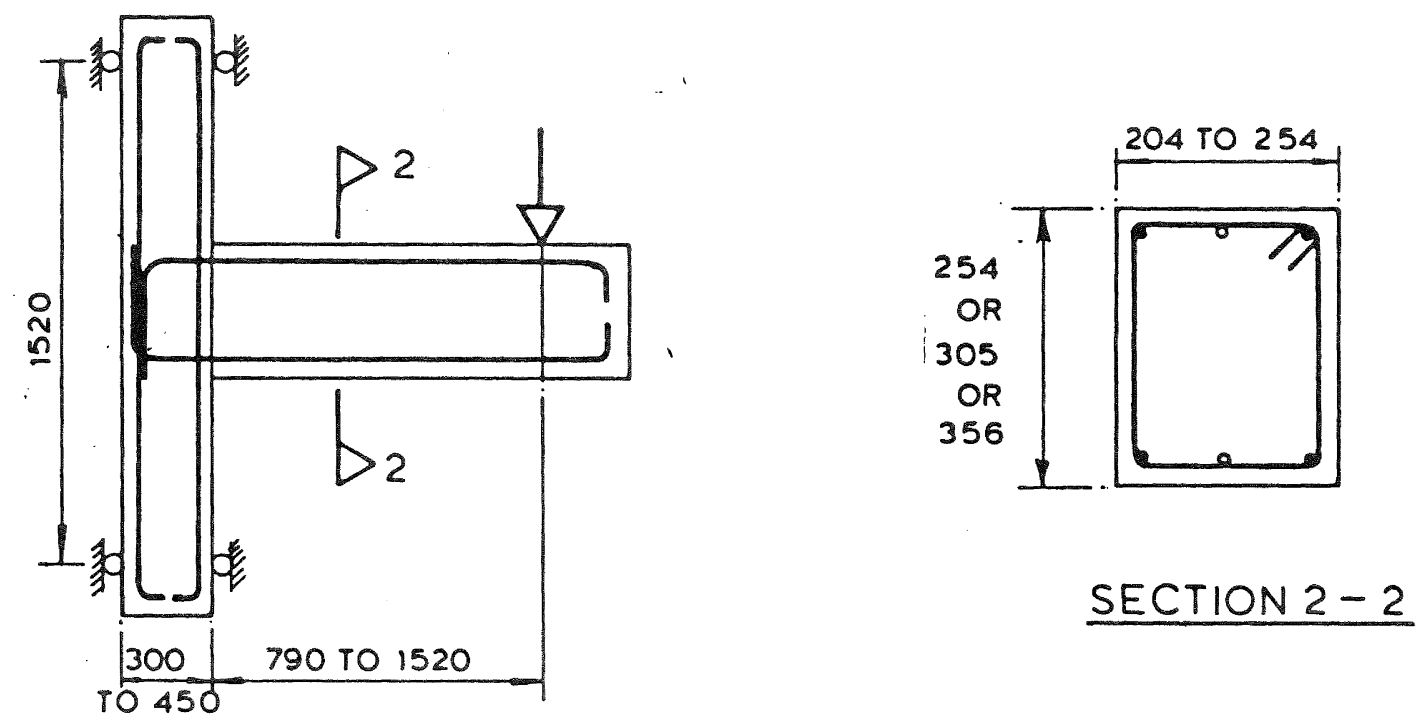

(b) BEAMS TESTED BY SCRIBNER AND WIGHT (7)
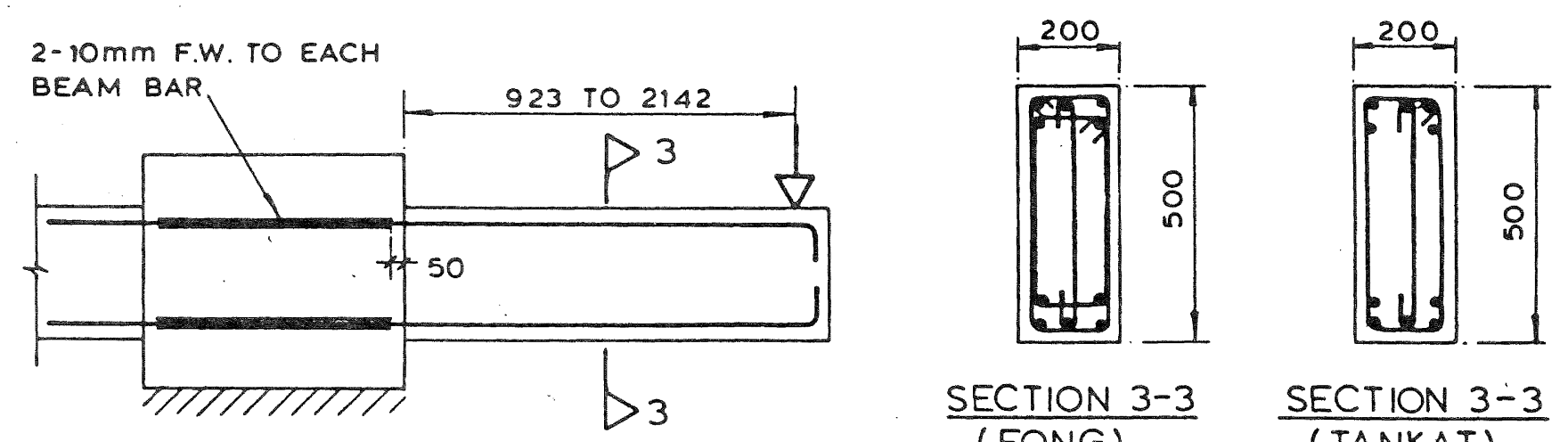

$\frac{\text { SECTION } 3-3}{\text { (FONG) }} \quad \frac{\text { SECTION } 3-3}{\text { (TANKAT) }}$

(c) BEAMS TESTED BY FENWICK, FONG, TANKAT \& THOM $(11,13)$
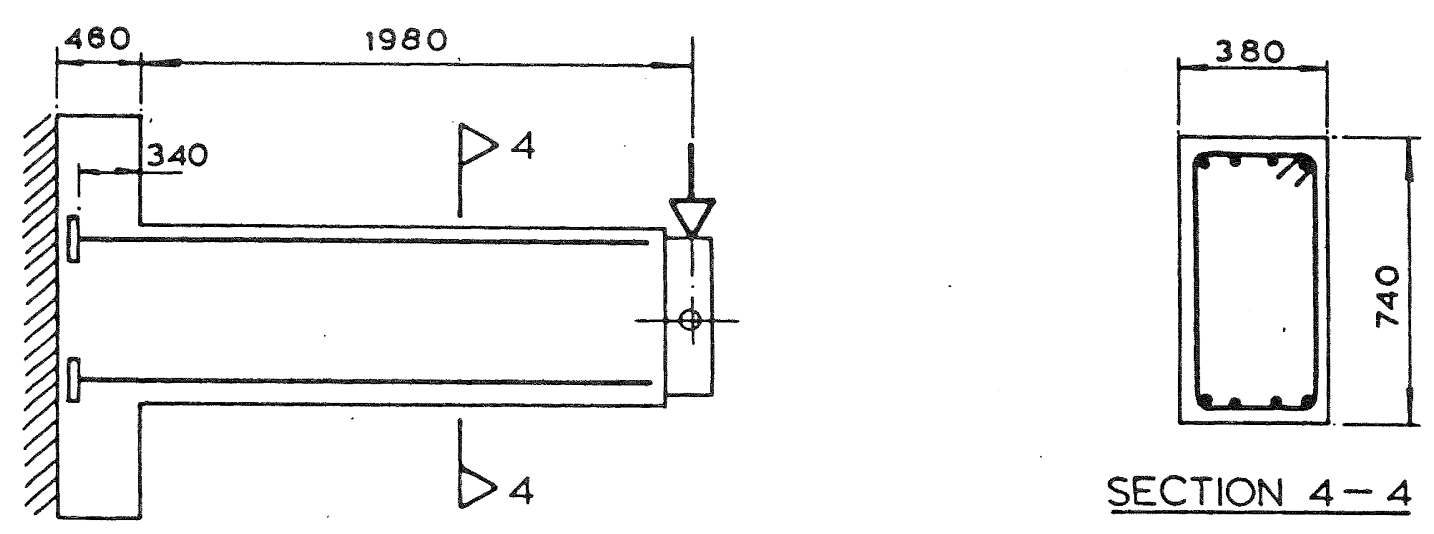

(d) BEAMS TESTED BY POPOV AND BERTERO (15)

Fig. 7 - Details of Beam Tests 
the yield and pull-out of the reinforcement in this zone was determined. After one or two cycles this proportion settled down to fairly constant value. In beams reinforced with $19 \mathrm{~mm}$ bars (No. 6) this proportion averaged 0.45, except for beam 66-32-RV5 where the value was close to 0.60 . With the $25 \mathrm{~mm}$ bars (No. 8) the corresponding value averaged 0.51 , and for beams with a mixture of 25 and $19 \mathrm{~mm}$ bars it was 0.52 . To assess the energy which is dissipated by the beam alone it was assumed that the ratio of energies dissipated in the beam and in the springing was equal to the ratio of the deflections arising from the deformations in these two zones. The proportion of the total energy dissipated in the beam is tabulated as value "p" in table 2 .

In the tests carried out by scribner and wight (7) the beam was sprung from a column as shown in Fig. 8b. Photographs of the specimens taken at the end of the test showed that in all cases the joint zone remained intact, and the degradation occurred in the beam. However, the beam flexural reinforcement would have yielded back through the joint zone to part way round the bend in the bars. The anchorage conditions were more favourable in these tests than in the units tested by Brown. The proportion of energy dissipated by the beam was likely to be in the range of 0.5 to 0.75 of the total value. For the purpose of analysis a figure of 0.65 was assumed for these tests.

In the beams tested by Fong (11, 12) and Tankat (13) two lomm bars were fillet welded to each beam flexural reinforcement bar starting at a point $50 \mathrm{~mm}$ from the critical beam section, see Fig. 7c. This detail was intended to limit the yield extension of the reinforcement in the anchorage zone. However, as this $50 \mathrm{~mm}$ length would have yielded, approximately 15 percent of the energy would have been dissipated in this zone. In the analysis it has been assumed that a proportion of 0.85 of the total energy was dissipated in the beam.

The test specimen referred to as unit 2 in tables 1 and 2 was an internal beam column sub-assembly (14). Two additional lomm bars were welded to each bar of flexural reinforcement in the beams close to the column and extended through the joint zone. With the detail that was used the column and joint zone remained elastic during the test, and yielding was confined to the hinge zones in the two beams. In the analysis the average value for the two beams has been used as a single result.

In the beam tests reported by Popov (15) the flexural reinforcement was anchored in the column by welding it to steel plates located approximately $340 \mathrm{~mm}$ from the column face, see Fig. $7 \mathrm{~d}$. In these tests the beam depth was $650 \mathrm{~mm}$, and it was considered that the proportion of energy dissipated by the beam would be in the range of 50 to 70 percent. In the analysis a proportion of 0.61 was assumed. the energy dissipated by each test unit from the load deflection diagrams. The results of these measurements are tabulated as the $E_{u}$ values in table 1 .

In the test series carried out by Brown (9), identical pairs of beams were made so that the influence of different loading histories on their behaviour could be studied. In the beams with the label RV5 the amplitude of displacement was initially close to half that applied to the companion beam which had a label of RV10. To obtain a failure in several of the RV5 beams the displacement amplitude was increased after 12 load cycles. These tests show that less energy was dissipated at failure in the beams which were subjected to the greater displacement amplitudes. From this observation it was concluded that the energy dissipated by a beam when the displacement is large has a greater effect on strength degradation than the same amount of energy dissipated when the displacement is small. $A$ weighting factor $\mathrm{k}$ was introduced to allow for this effect. Instead of summing the dissipated energy the sum of $k$ times the incremental energy was required. The value of $k$ was defined so that it was less then unity for small deflections, or hinge rotations, and greater than unity for large deflections.

To obtain some results against which different functions for $k$ could be checked the load deflection curves for the tests were re-examined. Each curve was divided into bands, with the width of each corresponding to a deflection due to deformation in the beam of $0.01 \mathrm{~L}^{\prime}$ where $L '$ was the distance from the critical section for the beam to the point where the deflection was measured. To allow for the deflection arising from deformation in the springing the band width for the test unit was taken as $.01 \mathrm{~L} / \mathrm{p}$. The proportion of the total energy dissipated in each band was found, and the results are given in table 2 .

Several different trial functions for $k$, which took the form:

$$
\mathrm{k}=\mathrm{C}+(\mathrm{nQ})^{2}
$$

were checked against the experimental data by running out a series of linear regression analyses. In this equation $C$ was less than unity, $Q$ was a constant and $n$ was the band number $(1,3,5$ etc) as shown in Fig. 9. For the purpose of interpreting the test results a single value of $K$ can be found to represent the $k$ function. This value is given by:

$\mathrm{k}=\sum e_{i} k_{i}(n=1,3,5,7,9$, and 11)

where $e_{j}$ is the proportion of energy dissipated in the band with a number equal to $i$, and $k_{i}$ is the corresponding value obtained from equation 9.

Of the thirty eight beams that were included in this study six did not show clear evidence of having reached the point where the strength had degraded to the $\mathrm{V}_{\text {yc }}$ value. These results were neglected 
when the failure criteria was derived. From the remaining 32 beams a series of initial linear regression analyses indicated that equations of the form:

$\theta=-A \frac{f d y c}{f^{\prime} c}+B$

and

$\theta=\frac{E_{b}}{M_{y c}}\left(\frac{f}{275}\right)^{h}\left(\frac{s}{4 d_{b}}\right)^{f}\left(\frac{A_{\ell}}{8 A_{v_{1}}}\right)^{g}$ H.K.

could be used to represent the general trend of the experimental values. In equation $11, E_{\text {was }}$ we energy dissipated in the beam (equal to $\mathrm{p} \mathrm{E}_{\mathrm{u}}$ ) at the stage where strength degradation occurred, Mycav is the average value of the moment strengths for positive and negative flexure, $K$ is the factor which allows for the loading sequence and $H$ is a value which allows for whether the stirrups in the beam yield or not.

The value of $\theta$ in equation 11 is arranged so that the terms which modify the $\left(E_{b} / M_{y c}\right)$ value are close to unity in a typical beam reinforced with 275 grade flexural reinforcement and which is subjected to plastic hinge rotations of $\pm 2^{\circ}$.

By carrying out a large number of linear regression analyses on a programmable calculator the appropriate coefficients were found for equations 9,10 , and 11 . The resultant equations are:

$\theta=-4.24 \frac{f_{\mathrm{dyc}}}{\mathrm{f}_{\mathrm{C}}}+0.93$

$\theta=\frac{E_{b}}{M_{y c a v}}\left(\frac{f y}{275}\right)^{-\frac{1}{2}}\left(\frac{s}{4 d_{b}}\right)^{1.25}\left(\frac{A_{\ell}}{8 A_{V 1}}\right)^{1 / 3} H \mathrm{~K}$.

and

$K=\Sigma\left(0.6+(0.34 n)^{2}\right) e_{n}$

where $n$ is the band member defined in Fig. 9 and $e_{n}$ was the proportion of the total energy dissipated in the band. The value of $\mathrm{H}$ in equation 13 was taken as unity for the case where the stirrups in the hinge zone yielded (the normal situation) and as 0.67 for non yielding stirrups.

If criteria based on these equations are to be used in a dynamic analysis situation the single value of $K$ needs to be replaced by a continuous function as previously outlined. Equation 14 is equivalent to:

$k=0.6+\left(68 \delta / L^{\prime}\right)$

where $\delta$ is the beam deflection measured at a distance of $L^{\prime}$ from the critical section of the cantilever beam. However, for use with frame structures the ratio of $\delta / L^{\prime}$ should be related to a value which can be conveniently measured, such as the hinge rotation. It would have been preferable to have related $k$ directly to measured hinge rotations, but this was not possible as the necessary measurements were only made on a few tests. For the purpose of making this conversion it is assumed that an average of $25 \%$ of the deflection in the tests was due to shear. With this assumption equation 15 can be re-written as:

$k=0.6+(90 \beta)^{2}$

where $\beta$ is the hinge rotation in radians.

The fit of equation 12 to the experimental results is shown in Fig. 10. The correlation coefficient is 0.8 . More experimental results would improve the confidence that could be placed in the equation, and in particular further tests are required to evaluate the $k$ factor which allows for the sequence and amplitude of displacements applied in the tests.

In recognition of the scatter of the experimental results, and of the uncertainty as to how well the test conditions represent the actual actions in hinge zones under seismic conditions, it is necessary to adopt a design criterion which lies on the conservative side of the empirically derived equation. The following tentative design criterion is suggested, and it is compared with the experimental results in Fig. 10.

$$
\begin{gathered}
\theta=-4 f_{\text {dyc }} / f_{c^{\prime}}+0.75 \\
\theta=\frac{\left(\sum \Delta E_{b} \cdot k\right)}{M_{\text {ycav }}}\left(\frac{f_{y}}{275}\right)^{-\frac{1}{2}}\left(\frac{s}{4 d_{b}}\right)^{1.25} \\
\left(\frac{A_{l}}{8 A_{V^{1}}}\right)^{1 / 3} \mathrm{H}
\end{gathered}
$$

where

$k=0.6+(90 B)^{2}$

As with all empirical equations it is limited to the range of variables covered by the test beams. These are listed below:

(1) the cylinder strength of the concrete varied from 25 to $50 \mathrm{MPa}$,

(2) the ratio of the diagonal compression stress $f_{\text {dyc }}$ divided by the cylinder strength varied from 0.05 to 0.20 ,

(3) the ratio of the stirrup spacing divided by the diameter of the flexural reinforcing bars $s / d_{b}$ lay in the range of 2 to 7 ,

(4) the ratio of the area of reinforcement, which was restrained against buckling by one stirrup leg, divided by the area of the stirrup leg $A_{l} / A_{V^{l}}$ varied from 4 to 15 ,

(5) the flexural reinforcement yield stress levels lay between 275 and $415 \mathrm{MPa}$,

the amplitude of rotation imposed on the beams in general did not 
exceed $\pm 2.5^{\circ}$, and

(7) the ratio of the areas of flexural reinforcement used on each side of the beam lay within the limits of 0.56 to 1.8 .

\section{CONCLUSIONS:}

(1) Under inelastic cyclic conditions the flexural compression force is resisted predominately by the reinforcement on the compression side of the member.

(2) The shear in the hinge zone is resisted by a truss-like action in which the concrete resists the diagonal compression forces and the stirrups act as ties.

(3) From the compatibility and equilibrium requirements of the hinge zone it is shown that when a certain critical curvature is reached the stirrups yield. Additional permanent extension of the stirrups occurs whenever this limit is exceeded. The growth in length of the stirrup increases the shear deformation and the associated stiffness degradation of the beam.

(4) After a number of repeated cyclic displacements are applied to the hinge zone its strength degrades as a result of disintegration of the concrete in the web and buckling of the flexural reinforcement.

(5) An analysis of test results published in the literature shows that the energy which can be dissipated by a hinge zone before strength degradation increases with:

a) an increase in the flexural strength of the member,

b) a decrease in the shear to moment ratio acting on the hinge,

c) an increase in the yield point of the flexural reinforcement,

d) an increase in the size of the stirrups,

e) a decrease in the spacing of the stirrups, and

f) a reduction of the amplitude of the rotations applied to the hinge zone.

\section{ACKNOWLEDGEMENTS:}

The assistance received from Ove Arup and Partners in the preparation of the diagrams and the typing for this article is gratefully acknowledged.

\section{REFERENCES :}

(1) Agrawal, G.L., Tulin, L.G., and Gerstle, K.H., "Response of Doubly Reinforced Concrete Beams to Cyclic Loading". Journal of the American Concrete Institute,
Vol. 62, No. 7, July 1965 pp. 823-835.

(2) Brown, R.H., and Jirsa, J.O. "Reinforced Concrete Beams under Reversed Loading", Journal of the American Concrete Institute, Vol. 68, No. 5, May 1971, pp. 380-390.

(3) Park, R., Kent, D.C., and Sampson, R.A., "Reinforced Concrete Members with Cyclic Loading", Proceeding ASCE, Structural Division, Vol. 98 , No. ST7, July 1972, pp. 1341-1360.

(4) Fenwick, R.C., and Thom, C.W. "Shear Deformation in Reinforced Concrete Beams Subjected to Inelastic Cyclic Loading", University of Auckland, School of Engineering Report, No. 279, June 1982 .

(5) Bull, I.N., "The Shear Strength of Relocated Plastic Hinges", Department of Civil Engineering Report, No. 78 - 11, University of Canterbury, February 1978.

(6) Bertero, V.V., Popov, E.P., and Wang, T.Y., "Hysteretic Behaviour of Reinforced Concrete Flexural Members with Special Web Reinforcement", Earthquake Engineering Research Center, University of California, Berkeley, Report No. EERC 74-9, Aug. 1974.

(7) Scribner, C.F., and Wight, J.K., "Delaying Shear Strength Decay in Reinforced Concrete Flexural Members Under Large Load Reversals", Department of Civil Engineering, University of Michigan, Report No. UMEE, 78R2, May 1978.

(8) Sinha, B.P., Gerstle, K.H., and Tulin, L.G., "Stress-strain Relationships for Concrete Under Cyclic Loading", Journal of the American Concrete Institute, Vol. 61, No. 2, February 1964, pp. 195-212.

(9) Brown, R.H., "Reinforced Concrete Cantilever Beams under Slow Cyclic Loading", Ph. D. Thesis, Rice University, Houston, Texas, April 1970 .

(10) Ismail, M.A.F., "Bond Deterioration in Reinforced Concrete under Cyclic Loading", Ph.D. Thesis, Rice University, Houston, Texas, February 1970 .

(11) Fong, A., "The Behaviour of Reinforced Concrete Beams under Cyclic Loading", M.E. Thesis, University of Auckland, N.Z., 1978.

(12) Fenwick, R.C., and Fong, A., "The Behaviour of Reinforced Concrete Beams under Cyclic Loading", Bulletin of the N.Z. National Society for Earthquake Engineering, Vol. 12, No. 2, June 1979, pp. 158-167.

Fenwick, R.C., Tankat, A.T., and Thom, C.W., "The Deformation of Reinforced Concrete Beams Subjected 
to Inelastic Cyclic Loading -

Experimental Results", University of Auckland School of Engineering, Report No. 268, October 1981.

(14) Fenwick, R.C., "Seismic Resistant Joints for Reinforced Concrete Structures", Bulletin of the New Zealand National Society of

Earthquake Engineering, Vol. 14, No. 3, September 1981, pp 145-159.

(15) Popov, E.P., Bertero, V.V., and Krawinkler, H., "Cyclic Behaviour of Three Reinforced Concrete Flexural Members with High Shear", Earthquake Engineering Research Center, University of California Berkeley, Report No. EERC 72-5, October 1972 .

(16) Park, R., and Paulay, T. "Reinforced Concrete Structures - Chapter 7" Published John Wiley and Sons, 1975.

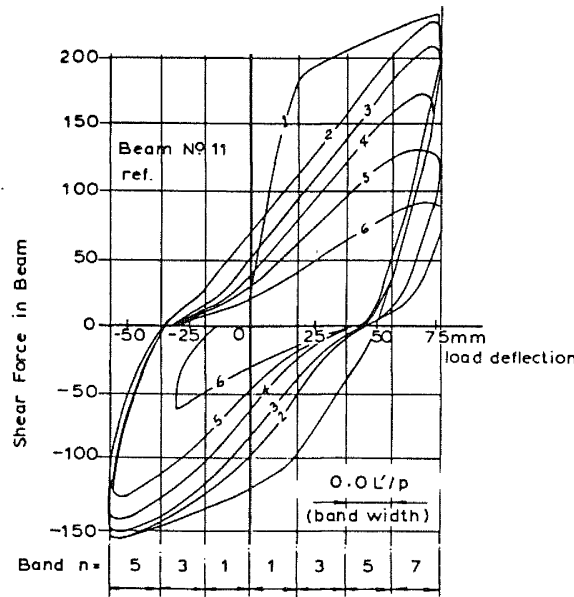

Fig. 9 - Load Deflection Curve Divided into Bands.

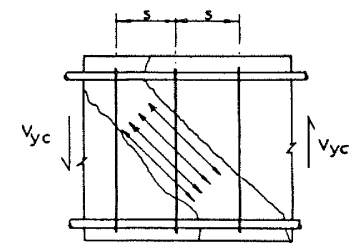

(a) Crack Pattern

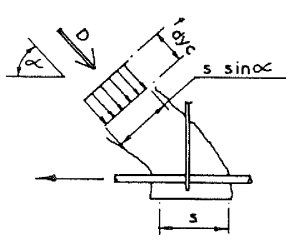

(b) Web Forces

Fig. 8-Diagonal Forces and Stresses in Beam Web

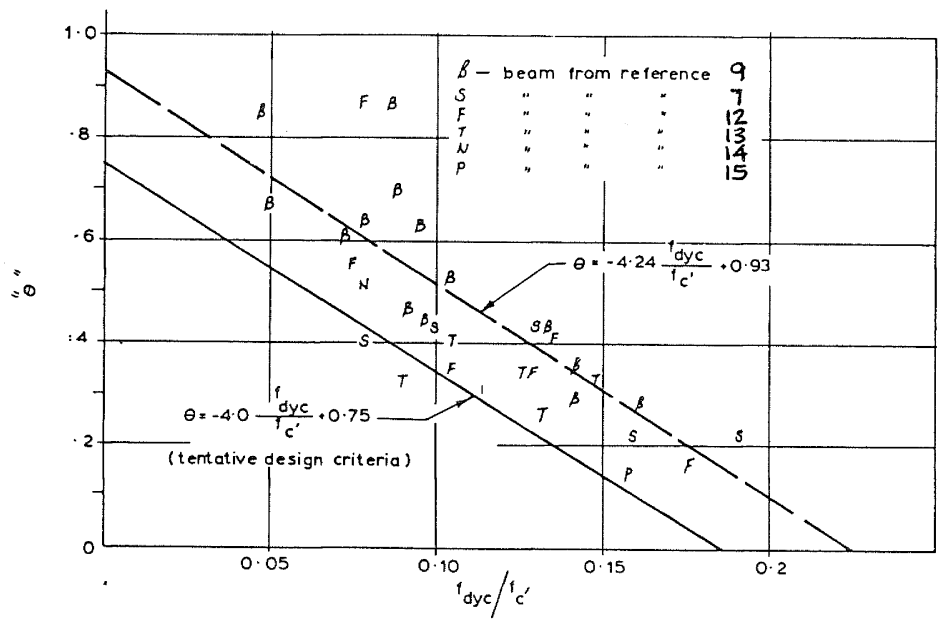

Fig. 10 - Experimental Values Compared with Regression Equation and Tentative Design Criteria 